Research, Society and Development, v. 9, n. 9, e26996542, 2020

(CC BY 4.0) | ISSN 2525-3409 | DOI: http://dx.doi.org/10.33448/rsd-v9i9.6542

\title{
Sequência didática para estudo dos conceitos de Mecânica por meio do Arduino
}

Didactic sequence for the study of the concepts of Mechanics using Arduino Secuencia didáctica para el estudio de conceptos Mecánicos con Arduino

Recebido: 09/07/2020 | Revisado: 29/07/2020 | Aceito: 31/07/2020 | Publicado: 09/08/2020

João Cláudio Nunes Carvalho

ORCID: https://orcid.org/0000-0001-8619-0869

Instituto Federal do Ceará, Brasil

E-mail: joao.carvalho@ifce.edu.br

Nickyson Brandão Everton

ORCID: https://orcid.org/0000-0003-0618-8203

Instituto Federal do Ceará, Brasil

E-mail: nickysonbrandao@gmail.com

\section{Resumo}

Este trabalho traz a descrição e aplicação de uma sequência didática, envolvendo conceitos de mecânica básica em uma escola de ensino médio na cidade de Acaraú-CE. Tal sequência didática é baseada na proposta da Aprendizagem Significativa, pautada por David Ausubel, segundo a qual a aprendizagem torna-se palpável ao aluno quando esta estreita o seu conhecimento prévio com o que se deseja aprender a partir da mediação do professor. A metodologia consiste na utilização de um experimento prático, para contextualização de conceitos de velocidade média, desenvolvido com apoio da plataforma Arduino. Os dados foram coletados à partir dos testes aplicados, atividades desenvolvidas e relatos espontâneos ou sugeridos a partir dos discentes. Os testes foram realizados também em outra turma, na qual foi utilizada a metodologia tradicional no intuito de comparação de desempenho. O objetivo deste trabalho é apresentar uma metodologia alternativa, para que estes conceitos sejam trabalhados de uma forma mais didática.

Palavras-chave: Sequência didática; Arduíno; Ensino de Física.

\footnotetext{
Abstract

This research presents a description and application of a didactic sequence, that involves basic mechanics concepts in the high school in the city of Acaraú-CE. Such didactic sequence is based
} 
on the proposal of Meaningful Learning, published by David Ausubel, according to which, learning becomes palpable to the student when he starts the prior knowledge with whom he wishes to learn, through teacher mediation. The methodology consists of using a practical experiment, to contextualize medium speed concepts, developed with support from the Arduino platform. The data were collected from the applied tests, developed activities and spontaneous or suggested reports from the students. The tests were applied in another class, in which the traditional methodology was used in order to compare performance. Thus, we propose here an alternative didactic sequence that, in addition to arousing the interest of students in the teaching of science, can favor the pedagogical action of the teacher.

Keywords: Teaching sequence; Arduino; Physics teaching.

\section{Resumen}

Este trabajo presenta la descripción y aplicación de una secuencia didáctica, que involucra conceptos básicos de mecánica en una escuela secundaria en la ciudad de Acaraú-CE. Esta secuencia didáctica se basa en la propuesta de aprendizaje significativo, guiada por David Ausubel, según la cual el aprendizaje se vuelve palpable para el estudiante cuando estrecha sus conocimientos previos con lo que uno desea aprender con la mediación del maestro. La metodología consiste en utilizar un experimento práctico para contextualizar conceptos de velocidad media, desarrollado con el soporte de la plataforma Arduino. Los datos fueron recolectados de las pruebas aplicadas, actividades desarrolladas e informes espontáneos o sugeridos por los estudiantes. Las pruebas se aplicaron en otra clase, en la que se utilizó la metodología tradicional para comparar el rendimiento, y se encontraron diferencias. Por lo tanto, se propone una secuencia didáctica alternativa que, además de despertar el interés de los estudiantes en la enseñanza de las ciencias, puede favorecer la acción pedagógica del profesor. Palabras clave: Secuencia didáctica; Arduino; Enseñanza de la Física.

\section{Introdução}

A Física está relacionada com o estudo de leis, modelos matemáticos, representações e percepção de fenômenos naturais por meio da observação e da experimentação, procurando fazer conexões com esquemas lógicos através de equações matemáticas, o que pode trazer como consequência uma mudança de comportamento ou de ótica da vida humana.

Os filósofos gregos já faziam esta relação da natureza com a percepção humana, explicando as causas e consequências dos fenômenos com base na filosofia. Aristóteles 
explicava que a queda dos corpos estava relacionada com a ideia de que os corpos possuem um "lugar natural", ou seja, se uma pedra caia a explicação era a de que o lugar natural da pedra era a superfície mais baix. O mesmo argumento poderia ser utilizado para o ar ou as nuvens, que possuem seu "lugar natural" na esfera celeste por ser mais leve (Peduzzi, 1996).

Galileu mostrou através do método experimental, que dois corpos de pesos diferentes em queda livre (ou sem atrito significativo com o ar) atingem o solo no mesmo instante de tempo. Este fato era contrário as ideias de Aristóteles, que afirmava que quanto mais pesado um corpo, mais rapidamente chegaria ao solo. Estas ideias não eram questionadas publicamente até então, haja vista a reputação do filósofo quanto às suas verdades que eram difíceis de refutar (Ferreira, 2004).

Todas estes princípios, partiram da curiosidade em conhecer os fenômenos da natureza, o que de fato é uma característica do ser humano. As crianças desde os primeiros anos de vida manifestam uma curiosidade natural e desejo de saber para compreender e dar sentido ao mundo. Quando chegam à escola, já apresentam ideias, modelos interpretativos, explicações sobre o mundo físico-natural que as cercam, fruto de uma longa elaboração pessoal espontânea, baseada na experiência sensível de todos os dias que conferem sentido às suas experiências pessoais, conforme mencionado por autores como Piaget \& Fiúza (2005), Arce (2011) e Santana (2018). Assim, quando elas são devidamente instigadas, por diferentes atividades, sejam elas experimentos, utilização de jogos, simulações, entre outras, os estudantes podem demonstrar uma maior facilidade em aprender (Bruno, 2009).

No entanto, quando esta curiosidade não é estimulada da forma mais adequada pelo professor, uma resistência à aprendizagem por parte do estudante pode vir à tona. A dificuldade em aprender Física apresentada por muitos alunos que chegam ao Ensino Médio passa por diferentes fatores seja intra-classe, seja extraclasse (Ricardo \& Freire, 2007)(Moreira, 2017). Muitos desses podem convergir em um resultado no qual o aluno chega desmotivado por razões como falta de perspectiva de futuro, falta de cuidado por parte da família ou mesmo por julgar a escola e as aulas desinteressantes, onde muitas vezes o foco são os exames, como vestibular e Enem (Paiva et al., 2018) (Schroeder, 2007) (Parisoto \& Hilger, 2016). Muitos trabalhos já realizados, mostram que o aspecto motivacional é fundamental no processo de aprendizagem, sendo inclusive um fator decisivo para o desempenho dos estudantes (Bzuneck \& Boruchovitch, 2009)(Perassinoto et al., 2013)(Crestani, 2015)(Kaulfuss \& Boruchovitch, 2016).

A literatura traz muitos trabalhos onde simulações computacionais são realizadas com auxílio do Arduino para análise de fenômenos físicos diversos. Entre estes, podemos citar os 
encontrados nas referências (Rubim Junior, 2014) (Segatto et al., 2016) (Vidal, 2018) (Nunes, 2018) (Mourão, 2018). Todos estes trabalhos possuem aplicação na área do ensino da Física, utilizando simulações e/ou experimentos de baixo custo, tornando significativo o processo de ensino-aprendizagem.

As aulas de laboratório ou que possuem recursos envolvendo práticas experimentais costumam chamar mais a atenção destes alunos com dificuldades, de forma que podem favorecer uma maior protagonização por parte destes. Porém, somente aplicar experimentos deliberadamente pode não ser adequado para uma aprendizagem significativa no aluno.

Este trabalho propõe que as aplicações experimentais estejam harmonizadas com uma Sequência Didática (SD), trazendo um equilíbrio entre teoria, resolução de exercícios, utilização de imagens, vídeos, bem como fazer uma conexão com o cotidiano dos alunos. Dentro de nossa SD, será apresentado um experimento, criado por meio do uso de uma placa eletrônica denominada Arduíno (que se trata de uma plataforma alternativa para aquisição automática de dados).

\section{Referencial Teórico}

\subsection{Aprendizagem Significativa}

Em sua teoria, Ausubel defende que a aprendizagem torna-se significativa quando o conteúdo abordado é incorporado ao aluno de modo que haja completude a um conhecimento previamente compreendido. Segundo Ausubel, para que ocorra a aprendizagem significativa é fundamental que estes organizadores prévios (subsunçores) sejam bem ancorados antes da abordagem de um novo conteúdo, facilitando assim a reflexão por parte do aluno (Ausubel, 2003). Portanto, para que a aprendizagem se torne significativa para o aluno é necessário que o professor apure estes subsunçores. Estas bases prévias se destinam a servir como pontes cognitivas entre aquilo que o aprendiz já sabe e o que ele deve saber para que possa aprender significativamente o novo conteúdo que é proposto.

Desta forma, a aprendizagem torna-se algo progressivo, pois cada novo conceito estabelecido por parte do aluno irá ancorar-se a outro anteriormente existente, que por sua vez servirá de base para um ganho de conhecimento mais elevado. Podemos enumerar três requisitos essenciais para uma aprendizagem significativa (Tavares, 2004):

- a oferta de um novo conhecimento estruturado de maneira lógica; 
Research, Society and Development, v. 9, n. 9, e26996542, 2020

(CC BY 4.0) | ISSN 2525-3409 | DOI: http://dx.doi.org/10.33448/rsd-v9i9.6542

- a existência de conhecimentos na estrutura cognitiva que possibilite a sua conexão com o novo conhecimento;

- a atitude explícita de apreender e conectar o seu conhecimento com aquele que pretende absorver.

Dessa forma, torna-se importante uma motivação também por parte do aluno, para que o processo de ensino possa ocorrer da melhor forma possível. Nessas circunstâncias, o professor é um deste agentes motivadores, pois a forma de planejar e executar suas aulas pode despertar o interesse nos alunos para a aprendizagem.

\subsection{Dificuldades no Ensino da Física nas Óticas Docente e Discente}

Relacionar o conteúdo com a vivência social do aluno é uma tarefa importante no Ensino de Física, o que pode se tornar um pouco mais difícil quando alguns fenômenos possuem uma abstração significativa. Porém, quando há uma relação plausível entre o que é ensinado e o que é vivenciado, percebe-se uma participação e interesse maior por parte dos alunos (Von Korff et al., 2015)(Etkina, 2015)( Pinheiro et al.,2019).

Adolescentes de uma maneira geral se distraem com facilidade, mas por outro lado são curiosos, característica que pode ser aproveitada pelo professor, desde que este introduza metodologias que despertem a atenção do aluno, como por exemplo a utilização de práticas experimentais e/ou simulações computacionais (Laburú, 2016). Alguns exemplos de aulas que possuem este caráter prático podem ser atividades interativas baseadas no uso do computador, análise e interpretação de dados, elaboração de modelos, interpretação de gráficos, pesquisas bibliográficas, entrevistas e construção de protótipos (Rosito, 2013).

Neste sentido, o professor de Física pode utilizar da ideia de confeccionar experimentos de baixo custo ou trabalhar com simulações computacionais junto a seus alunos, tanto como uma forma de engajamento da turma no processo de ensino-aprendizagem, como uma forma de participação crítica, ativa e construtiva.

\subsection{Experimentos computacionais como facilitadores de aprendizagem}

A Física não pode se limitar apenas a perguntas e respostas objetivas, pois as mesmas podem não ser reflexo da vida real do discente, assim orienta os Parâmetros Curriculares 
Nacioanis (PCNs) (Brasil, 2002). Fazer o aluno encontrar soluções de um problema que ele não conhece, tratando a matéria estudada como se fosse apenas um jogo de números com fórmulas aleatórias sem nexo com a prática do cotidiano, pode fazer com que a Física se torne uma ciência entediante e não atrativa para o discente.

Experimentos muitas vezes facilitam e desmistificam alguma dificuldade que um conteúdo pode apresentar. Assim, a demonstração do experimento deve envolver o discente e valorizar os saberes que o mesmo já possui. Desta forma, o professor poderá despertar interesse para resolver um problema proposto pela atividade de ensino trabalhada (Bemfeito \& Vianna, 2009).

Uma barreira que é encontrada por professores e alunos no que se refere a utilização destes experimentos está no alto custo de equipamentos que compõem os laboratórios de ciências, bem como no valor de manutenção, o sucateamento de peças obsoletas, assim como a falta de capacitação dos professores para a utilização dos mesmos. Existem alternativas de baixo custo que podem suprir as carências mais simples e que podem ser encontradas no campo da robótica, entre elas, a plataforma Arduíno (que será explanada na seção 2.4).

Nesse cenário, a robótica é uma área que, sendo explorada com sua devida importância, pode trazer soluções bastante relevantes às dificuldades no ensino da Física. Robôs instigam a curiosidade de crianças e adultos, podendo ser considerados uma ferramenta que proporcionam o aprendizado de conceitos, tais como, os de física, matemática, geografia, programação entre outros, de forma simples e agradável (Perez et al.,2013).

A área de processamento de dados trabalha com instrumentos de coleta, que podem ter preços e finalidades variados. Nesse contexto, a placa de processamento de dados Arduino é uma plataforma que apresenta baixo custo, rico acervo de tutoriais e uma boa variedade de aplicações.

\subsection{Plataforma Arduino}

Essa plataforma teve origem na Itália, no ano de 2005, com autoria do professor Massimo Banz. O objetivo era a criação de um dispositivo barato, funcional e que fosse simples de programar, possibilitando o acesso a estudantes e projetistas amadores. A intenção do projeto era criar uma plataforma que pudesse realizar a programação e comunicação entre objetos interativos. A placa Arduino é constituída por um micro controlador ATMEL, portas de entrada e saída digitais, portas de entrada analógicas além de pinos capazes de fornecer níveis de tensão e aterrar pontos do circuito. A programação do microcontrolador é feita através 
do computador, por meio de um ambiente de desenvolvimento denominado Arduino IDE. A comunicação da placa é feita através de um cabo USB, utilizando uma porta serial do computador. A Figura 1 mostra uma placa de um dos modelos mais comuns disponíveis no mercado.

Figura 1: Placa Arduino UNO.

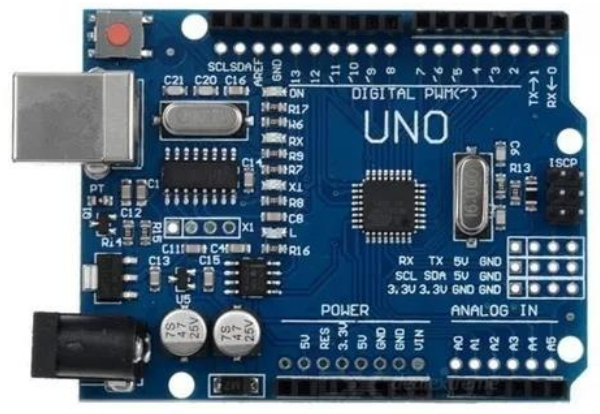

Fonte: Autoria própria.

O software Arduino IDE é utilizado para escrever e fazer upload de programas em placas compatíveis com Arduino e desse modo interagir com o que estiver conectado na placa (McRoberts, 2018). Estes programas são chamadas sketch, e consistem de duas partes (rotinas): a rotina de setup, que inicializa o sketch, e a rotina de loop, que normalmente contém o código principal do programa (como por exemplo, a função main() da linguagem C) (Reis, 2015).

A variedade de sensores que é encontrado no mercado, a relativa facilidade quanto ao uso dos softwares e montagem de sketches, bem como a precisão nos dados coletados, são alguns dos fatores levantados como vantagens ao uso do Arduino para o ensino de Física.

\section{Materiais e Métodos}

A metodologia utilizada neste trabalho envolve a pesquisa exploratória, usando o método qualitativo, fundamentado por Pereira et. al. (2018). Tal método foi empregado na aplicação da Sequência Didática nas turmas envolvidas nesta pesquisa.

\subsection{Atos da sequência didática}

Esta sequência foi dividida em seis atos, que foram aplicados em uma turma de primeiro ano ( $\left.1^{\circ} \mathrm{A}\right)$ do ensino médio, no ano de 2018 em uma escola estadual de educação profissional, situada na cidade de Acaraú-CE. 
Research, Society and Development, v. 9, n. 9, e26996542, 2020

(CC BY 4.0) | ISSN 2525-3409 | DOI: http://dx.doi.org/10.33448/rsd-v9i9.6542

No Primeiro Ato, aplicamos um teste no qual foi verificado o grau de conhecimento prévio dos discentes acerca do conteúdo. Para esta etapa, o tempo utilizado foi de 1 hora-aula (50 minutos).

No Segundo Ato da SD, o conteúdo de velocidade média foi explicado, fazendo toda a abordagem teórica e matemática, expondo as relações com os fenômenos do cotidiano, bem como suas respectivas unidades de medida. Para essa etapa foram necessárias 2 horas-aula. Os métodos empregados nesta etapa foram:

- imagens de automóveis se deslocando em rodovias;

- imagens de velocímetros;

- imagens de placas de sinalização de trânsito informando velocidade máxima permitida;

- imagens de atletas velocistas, esportes ou jogos que façam exibição de unidades de velocidade (seja do SI, convencionais ou de outros sistemas).

Neste ato foi essencial perceber se os estudantes conseguiam interpretar as unidades de medidas, além de compreender o porquê de cotidianamente não ser feito o uso da unidade padrão da velocidade adotada no sistema internacional de unidades.

O Terceiro Ato da SD consistiu na resolução de questões do livro didático, para isso a turma foi dividida em grupos. Nesta etapa foi necessária também, uma atenção às dificuldades que os alunos relatavam acerca da interpretação das questões. As questões selecionadas para este ato, estimulavam a compreensão do sistema físico no qual o problema estava situado. $\mathrm{O}$ professor agiu como mediador, ficando entre o aluno e a aprendizagem. Aqui, o professor buscou estimular a reflexão dos alunos diante dos problemas expostos, ajudando-se a interpretar melhor bem como os auxiliando nas dificuldades matemáticas.

O Quarto Ato da SD consistiu em um segundo teste, em forma de prova individual, onde foi verificado quanto o aluno pôde absorver dos conceitos já explanados acerca de velocidade média. Além disso, verificamos o quanto os alunos conseguiram abstrair e construir mentalmente, situações onde um determinado problema acontece, buscando a solução mais simples, na sua ótica, para a questão. Cabe ressaltar que foi importante dedicar ao aluno um tempo de descanso e maturação dos conceitos para que este, em seu tempo dedicado aos estudos em casa, pudesse absorver de forma individual as ideias relacionadas ao conteúdo abordado. 
Research, Society and Development, v. 9, n. 9, e26996542, 2020

(CC BY 4.0) | ISSN 2525-3409 | DOI: http://dx.doi.org/10.33448/rsd-v9i9.6542

Para a execução do Quinto Ato, foi realizada a aplicação do experimento "Trilha de Velocidade Média", cuja descrição será detalhada na próxima subseção 3.2. Para a apresentação do experimento, seguimos o seguinte passo a passo:

1.Posiciona-se o carrinho na trilha guiada antes do primeiro sensor;

2.Ao passar na frente do primeiro sensor de infravermelho, inicia-se a contagem de tempo na placa Arduino;

3.Continua-se a deslizar o carrinho ao longo da trilha até que este ultrapasse o segundo sensor;

4. Quando o carrinho passar pelo sensor posicionado $60 \mathrm{~cm}$ (marcado como $0,6 \mathrm{~m}$ ) à frente (esta distância fica a critério do professor; pode ser menor ou maior, de forma que seja modificado o código na rotina de loop), o contador será encerrado;

5.Realiza-se a leitura da velocidade, apresentada no monitor de saída a partir do computador.

É importante ressaltar que, grupo a grupo, os alunos manipularam o equipamento afim de apurar quais variáveis foram importantes para que se alcançasse maior ou menor velocidade e quais os obstáculos reais que impediam o deslizar do carrinho na trilha, bem como entender o funcionamento de cada componente conectado a placa Arduino.

No Sexto Ato e último desta $\mathrm{SD}$, foi realizado um último teste em forma de prova individual. O objetivo era averiguar se os alunos, após o uso do equipamento, conseguiam construir esquemas mentais de situações específicas, englobando o conceito de velocidade média. O teste consistia em cinco questões relacionadas ao experimento e a situações aplicáveis no dia a dia.

\subsection{Experimento com Arduíno}

Nesta subseção será descrito como foi criado o equipamento experimental de nome "Trilha de Velocidade Média", fundamental para este trabalho, o qual foi utilizado no Quinto Ato da SD.

Para a construção do experimento, foram necessários os seguintes itens:

- 1 tábua de madeira MDF ou afins de dimensões $120 \mathrm{~cm} 35 \mathrm{~cm}$;

- 1 placa processadora Arduino UNO; 
Research, Society and Development, v. 9, n. 9, e26996542, 2020

(CC BY 4.0) | ISSN 2525-3409 | DOI: http://dx.doi.org/10.33448/rsd-v9i9.6542

- 2 sensores de obstáculo reflexivo infravermelho para Arduino;

- Cabos jumper macho-macho, fêmea-fêmea e macho-fêmea para pinagem em Arduino;

- 1 notebook com Arduino IDE e seus respectivos drivers de acordo com seu sistema operacional

- 1 cabo USB A/B;

- 1 carrinho miniatura de ferro, bolinha ou qualquer outra partícula de fácil deslocamento.

$\mathrm{Na}$ tábua, foram posicionados ao lado da guia os sensores infravermelho distantes $60 \mathrm{~cm}$ entre si, um sensor posicionado de forma fixa, e outro de forma que sua posição pudesse ser variada. Após a correta pinagem dos sensores à placa, o código elaborado foi carregado.

Após a devida montagem, pinagem e fixação dos sensores e placa na tábua, a trilha terá aparência semelhante a Figura 2 abaixo:

Figura 2: Experimento "Trilha de Velocidade Média".

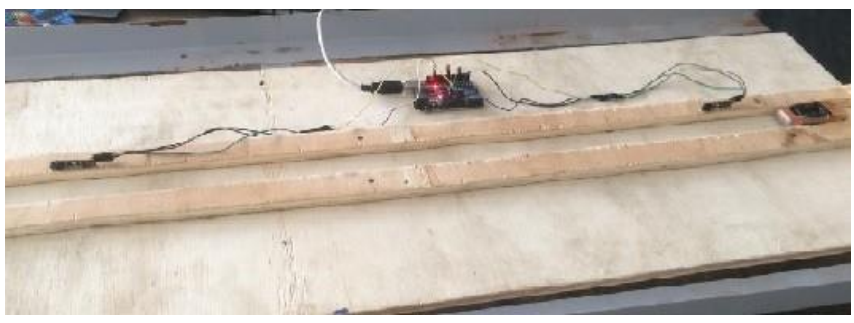

Fonte: Autoria própria.

Antes de executar o experimento, foi importante verificar cuidadosamente se os sensores não estavam próximos demais à guia da trilha, o que poderia causar uma colisão do projétil em algum sensor, danificando-o permanentemente. Todo teste e verificação de um experimento é importante antes de levar um equipamento à sala de aula.

\section{Resultados e Discussão}

Os resultados obtidos nesta pesquisa correspondem a dados qualitativos e quantitativos relacionados às perguntas respondidas pelos alunos no decorrer dos testes, bem como por meio de manifestações espontâneas de cada um, ao participarem de cada ato da SD. 
Research, Society and Development, v. 9, n. 9, e26996542, 2020

(CC BY 4.0) | ISSN 2525-3409 | DOI: http://dx.doi.org/10.33448/rsd-v9i9.6542

Por meio da análise dos dados, referentes ao Primeiro Ato, coletados na turma em que foi aplicada a SD, as principais palavras-chave utilizadas pelos alunos e a quantidade de ocorrências destas para responder à pergunta 1 do teste é mostrado no Quadro 1 a seguir:

Quadro 1: Palavras-chave da pergunta 1.

\begin{tabular}{|c|c|}
\hline \multicolumn{2}{|c|}{$\begin{array}{l}\text { Quais são as unidades físicas que você } \\
\text { conhece e costuma } \\
\text { utilizar sempre no seu cotidiano? }\end{array}$} \\
\hline "quilograma" ou "kg" & 42 alunos \\
\hline "hora" & 36 alunos \\
\hline "minuto" & 14 alunos \\
\hline "km/h" & 10 alunos \\
\hline "litro" & 10 alunos \\
\hline "metro" & 9 alunos \\
\hline
\end{tabular}

Fonte: Autoria própria.

Nesta turma todos conheciam a unidade padrão de massa, apesar de em sua maioria manifestarem uma relação inadequada com a grandeza peso, como tradicionalmente é observado. As grandezas de tempo "minuto" e "hora" foram amplamente citadas pelos alunos, e por meio das discussões estabelecidas na sala, eles demostraram conhecimento acerca da relação entres as diversas unidades de tempo.

Em um outro questionamento realizado com eles, ondeperguntamos: "Em um mapa, como a distância entre duas cidades é medida?", o resultado obtido é exibido no Quadro 2 a seguir:

Quadro 2: Palavras-chave da pergunta 5.

\begin{tabular}{|c|c|}
\hline $\begin{array}{l}\text { Em um mapa, co } \\
\text { duas cidades } \\
\text { é medida? }\end{array}$ & distância \\
\hline "A partir da & 24 alunos \\
\hline$"$ Regra de 3" & 18 alunos \\
\hline
\end{tabular}

Fonte: Autoria própria.

As palavras-chave extraídas a partir das respostas dadas pelos alunos nesta pergunta trouxeram um dado positivo acerca da interdisciplinaridade. Alguns alunos expuseram que este conteúdo já havia sido explorado na disciplina de Geografia em anos anteriores (no Ensino Fundamental). 
A aluna Amanda (ao citar um aluno, será usado um nome fantasia em itálico a fim de preservar a identidade do mesmo) ressaltou que a "a regra de 3 é muito simples e aplicável para esses problemas que envolvem mapas e outras situações como transformação de metro para quilômetro". Este relato foi muito importante pois sugere que a disciplina de Física pode e deve ser trabalhada de forma que seja aplicável em outras áreas, criando elos e favorecendo uma aprendizagem ainda mais significativa.

No Segundo Ato, foi abordado o conteúdo de velocidade média para a turma. A sala de aula foi organizada em grupos. Este ato foi desenvolvido ao longo de duas aulas, onde na primeira aula foi feita a explicação do conteúdo e na segunda aula foram trabalhados pequenos problemas, envolvendo as grandezas físicas apresentadas. Os dados levantados da aplicação deste ato são qualitativos.

Alguns relatos dos alunos podem ser destacados: O aluno José expôs de forma oral que "vê e compreende muito mais a velocidade $\mathrm{em} \mathrm{km} / \mathrm{h}$ do que $\mathrm{em} \mathrm{m} / \mathrm{s}$ no dia a dia" e que "até esta aula, nunca tinha ouvido falar nesta forma de medir velocidade”. Esta observação foi interessante, pois abriu uma discussão em sala relacionada ao fato de que a grandeza padrão de velocidade causa estranheza em algumas situações. Por exemplo, em provas de atletismo que envolvem velocidade, como corrida de 100m, ou em provas de natação. Em geral, nas transmissões de TV a velocidade dos atletas são expostos em $\mathrm{km} / \mathrm{h}$, apesar do comprimento da piscina ou da pista de atletismo ser medida em metros e o tempo de prova ser conferido em segundos.

Ao expor imagens de placas de sinalização aos alunos e questionando o porquê da unidade padrão de velocidade, m/s, não ser tão aplicada cotidianamente, algumas respostas foram levantadas por eles. O aluno Igor ressaltou espontaneamente que "não é 'fácil' usar o m/s porque o 1 segundo é pouco tempo para perceber 'no olho' o quanto um carro se deslocou. Já uma hora é mais fácil estimar". Em razão desta fala, o professor questionou ao Igor o motivo da unidade m/s não sr usada em provas de atletismo ou natação. A resposta do aluno foi que "as pessoas já são acostumadas com $\mathrm{km} / \mathrm{h}$ ". Tal resposta é interessante pois levanta o aspecto tradicional das unidades físicas no cotidiano, que são tratadas como padrão de forma equivocada em muitas situações.

Após este proveitoso debate, o conteúdo de velocidade foi explicado, associando-o à uma ilustração na lousa, de uma partícula que se desloca uma quantidade de espaço em uma trajetória em um intervalo de tempo. A partir desta explanação, foi apresentada a equação que define matematicamente a velocidade média de uma partícula, com sua unidade padrão sendo $\mathrm{m} / \mathrm{s}$.

$\mathrm{Na}$ aula seguinte, foram trabalhados situações problema envolvendo o conceito de velocidade média trabalhado na aula anterior, agregando a transformação da unidade padrão 
$\mathrm{m} / \mathrm{s}$ para $\mathrm{km} / \mathrm{h}$. Foram trabalhadas situações práticas do dia a dia dos alunos, como deslocamento de ônibus, carros ou motocicletas entre cidades conhecidas na região, bem como outras situações práticas individuais como sair de casa, ir à padaria e retornar.

No Terceiro Ato, foi trabalhada a estratégia de "célula de aprendizagem" ao organizar a turma em grupos de três ou quatro indivíduos afim de se ter uma melhor interação entre os alunos, fomentando a competência da cooperatividade. Foi proposta uma atividade a partir do livro didático adotado pela escola, onde foi sugerido a resolução de quatro questões relacionadas ao assunto. A forma de organização da turma, favoreceu trabalhar de forma mediadora e intervindo quando haviam dúvidas que exigiam uma maior interpretação.

Este ato foi trabalhado em duas aulas, sendo que a primeira foi destinada à resolução das atividades em grupo, realizando mediações quando necessário. Na segunda aula, a atividade foi corrigida, conferindo a partir de cada grupo quais as dificuldades encontradas na resolução da atividade. A partir da fala dos alunos, algumas dificuldades foram encontradas, as quais estão dispostas no Quadro 3.

Quadro 3: Dificuldades levantadas por alguns alunos na resolução de atividade no Terceiro Ato.

\begin{tabular}{|l|l|}
\hline Paula & $\begin{array}{l}\text { "Ainda tenho dificuldade de transformar } \\
\text { minutos em segundos" }\end{array}$ \\
\hline Francisco & "Aindanãoseiquandousarm/sou $\mathrm{km} / \mathrm{h} "$ \\
\hline Kelly & $\begin{array}{l}\text { "Tenho dificuldade de pegar os dados } \\
\text { do problema" }\end{array}$ \\
\hline Gabriel & $\begin{array}{l}\text { "Quando está explicando eu entendo, } \\
\text { mas quando chega a atividade, tenho dificuldade de } \\
\text { resolver" }\end{array}$ \\
\hline Ítalo & "Tenho dificuldade de usar a fórmula" \\
\hline
\end{tabular}

Fonte: Autoria própria.

Estas dificuldades trouxeram uma análise importante: muitos alunos manifestam problemas de leitura e interpretação dos exercícios, onde a dificuldade de visualização da situação física abordada foi um entrave, que se tornou difícil de contornar utilizando apenas métodos tradicionais de ensino. A dificuldade em matemática também se tornou um obstáculo significativo, pois a turma já apresentava deficiência na resolução de problemas simples envolvendo aritmética, soma de fração e substituição de dados em uma função.

No Quarto Ato foi aplicado um teste em forma de prova escrita contendo cinco questões, sendo quatro de múltipla escolha, onde os alunos precisaram aplicar os conceitos abordados anteriormente. O Quadro 4 mostra como foi o desempenho da turma. 
Research, Society and Development, v. 9, n. 9, e26996542, 2020

(CC BY 4.0) | ISSN 2525-3409 | DOI: http://dx.doi.org/10.33448/rsd-v9i9.6542

Quadro 4: Desempenho de acerto das questões da prova escrita.

\begin{tabular}{|c|c|}
\hline Questão & $\begin{array}{c}\text { Porcentagem de } \\
\text { Acerto }\end{array}$ \\
\hline 1 & $53,3 \%$ \\
\hline 2 & $80 \%$ \\
\hline 3 & $48,8 \%$ \\
\hline 5 & $62,2 \%$ \\
\hline
\end{tabular}

Fonte: Autoria própria.

Percebeu-se que a turma mostrou dificuldade e insegurança na resolução da maior parte das questões desta prova, visto que apenas duas destas alcançaram mais de $60 \%$ do total de alunos. A análise dos dados coletados nesta etapa da aplicação da SD favoreceu a reformulação de estratégias afim de propor soluções para os problemas identificados a partir das respostas de cada questão. O próximo ato foi fundamental para a tentativa de contornar esta situação.

Neste ato foi apresentado à turma o experimento "Trilha de Velocidade Média", onde os alunos, divididos nas células de estudo, interagiram com o experimento um grupo por vez. Os alunos eram instigados a brincarem com o equipamento, descobrir como funcionava, as unidades envolvidas e estimulados a propor desafios entre os colegas de célula.

Cada um dos 5 grupos de estudo tinha um tempo de 10 minutos para interagir com o experimento afim de encontrar as variáveis necessárias para um melhor rendimento da energia transferida ao carrinho. $\mathrm{O}$ desafio mais comum era descobrir como que o equipamento zerava a contagem de tempo para reiniciar a leitura. Outro desafio interessante, foi a disputa entre os grupos para saber que carrinho obteria a maior velocidade, essa questão da ludicidade acabou motivando-os. A partir da manifestação espontânea dos alunos durante a atividade lúdica, alguns relatos chamaram atenção:

- Rogério: "Fica mais fácil aprender sobre velocidade assim."

- Heloisa: “É difícil fazer o carrinho adquirir uma velocidade muito alta. Mas pra saber em $\mathrm{km} / \mathrm{h}$ tem que transformar."

- Amanda: "Mais fácil aprender com a prática do que só com 'dever'."

- Gabriel: "Se o senhor tivesse mostrado o experimento antes da prova tinha sido melhor." 
Research, Society and Development, v. 9, n. 9, e26996542, 2020

(CC BY 4.0) | ISSN 2525-3409 | DOI: http://dx.doi.org/10.33448/rsd-v9i9.6542

Estes relatos mostram que os alunos demonstram interesse e entusiasmo ao exercer uma atividade prática, principalmente quando o fazem de forma livre, com o professor apenas como mediador. Nesta circunstância, o aluno pode interagir com o equipamento e fazer suas próprias descobertas, aliando o seu conhecimento prévio à situação real que se encontra à sua frente. A Figura 3 mostra os alunos interagindo com o protótipo.

Figura 3: Grupo de alunos interagindo com o equipamento.

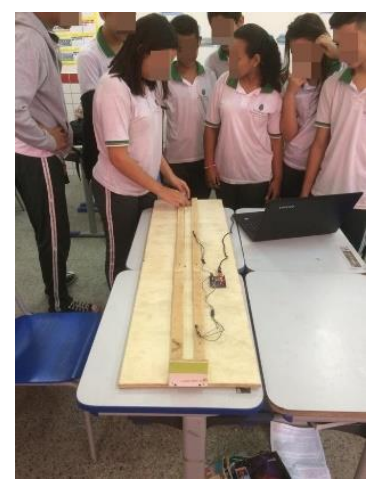

Fonte: Autoria própria.

Após a aplicação do experimento, parte lúdica da SD, o Sexto Ato, trouxe um exercício onde os alunos aplicaram conhecimentos de velocidade média relacionados ao equipamento experimental que trabalharam na aula anterior. As questões foram todas elaboradas a partir do uso da Trilha de Velocidade Média. A atividade foi entregue aos alunos, recolhida e as respostas foram analisadas de forma a perceber a quantidade de acertos em cada questão. A turma foi orientada a se organizar livremente para a execução da atividade, onde espontaneamente, escolheram os grupos de estudo já habituais. Estiveram presentes na data da atividade 41 alunos. O Quadro 5 a seguir mostra os resultados deste exercício em sala.

Quadro5: Resultados da Aplicação de Atividade no Sexto Ato.

\begin{tabular}{|l|l|l|}
\hline $\begin{array}{l}\text { Questã } \\
\text { o }\end{array}$ & $\begin{array}{l}\text { Acertos totais ou } \\
\text { parciais }\end{array}$ & Erros \\
\hline 1 & 36 alunos & 5 alunos \\
\hline 2 & 36 alunos & 5 alunos \\
\hline 3 & 36 alunos & 5 alunos \\
\hline 4 & 35 alunos & 6 alunos \\
\hline 5 & 36 alunos & 5 alunos \\
\hline
\end{tabular}

Fonte: Autoria própria.

Observando os dados, pode-se inferir que uma parcela significativa dos alunos, ao organizarem-se em grupos de estudo, demonstraram maior segurança para resolver os 
Research, Society and Development, v. 9, n. 9, e26996542, 2020

(CC BY 4.0) | ISSN 2525-3409 | DOI: http://dx.doi.org/10.33448/rsd-v9i9.6542

exercícios, oferecendo um resultado significativo quanto à quantidade de acertos nas questões. $\mathrm{O}$ aparente equilíbrio no número de itens acertados pelos alunos sugere que a turma de forma geral demonstrou mais segurança na resolução dos problemas em face a etapas anteriores.

Em paralelo a aplicação da sequência didática, tivemos na mesma escola uma turma de primeiro ano $\left(1^{\circ} \mathrm{C}\right)$ onde apenas a metodologia tradicional foi utilizada. A forma do desenvolvimento da temática na turma foi por meio de aulas expositivas e resolução de exercícios, exatamente iguais aos trabalhados ao longo da SD, bem como a aplicação da mesma prova realizada no Sexto Ato, para fins de comparação.

Os resultados da aplicação da atividade do sexto ato na turma do $1^{\circ} \mathrm{C}$ são apresentados no Quadro 6 a seguir:

Quadro 6: Resultados da Aplicação de Atividade do Sexto Ato na turma $1^{\circ} \mathrm{C}$.

\begin{tabular}{|l|l|l|}
\hline Questão & Acertos totais ou parciais & Erros \\
\hline 1 & 33 alunos & 10 alunos \\
\hline 2 & 31 alunos & 12 alunos \\
\hline 3 & 31 alunos & 12 alunos \\
\hline 4 & 29 alunos & 14 alunos \\
\hline 5 & 32 alunos & 11 alunos \\
\hline
\end{tabular}

Fonte: Autoria própria.

Pode-se perceber que os alunos desta turma, pelo fato de não haverem tido contato com o experimento e observando questões referentes a algo que não conheciam, buscaram resolver as questões de forma exclusivamente mecânica, obtendo resultados aquém em comparação à turma que teve contato com o experimento, imagens, diálogos e discussões, etc.

\section{Considerações Finais}

O presente trabalho trouxe uma análise da aplicação de uma Sequência Didática pautada na Aprendizagem Significativa e apoiada pelo uso de experimento, em uma escola de ensino médio na cidade de Acaraú-CE. A Sequência Didática elaborada foi aplicada em uma turma de $1^{\circ}$ ano médio e seus resultados foram comparados com outra turmam onde o método tradicional foi o utilizado.

A proposta de uma aprendizagem significativa feita por Ausubel traz ao professor uma reflexão em sua prática pedagógica. Fazer com que um conteúdo seja bem assimilado pelo aluno requer uma base de conhecimento prévio, os subsunçores, a fim de que ocorra a 
Research, Society and Development, v. 9, n. 9, e26996542, 2020

(CC BY 4.0) | ISSN 2525-3409 | DOI: http://dx.doi.org/10.33448/rsd-v9i9.6542

aprendizagem. A boa preparação das aulas em torno de uma sequência didática, aliada à prática experimental, fazendo com que o aluno ponha a "mão na massa" pode facilitar que este resultado seja alcançado.

O propósito deste trabalho foi fomentar a reflexão do professor de Física sobre sua prática pedagógica, trazendo uma alternativa para seu ensino a partir do Arduino. Ressaltamos, ainda, que a utilização dessa sequência em sala de aula não deve ser apenas para promover uma maior atenção por parte dos alunos. É importante também que haja um planejamento sobre como esse recurso pode ser trabalhado na aula, fazendo adaptações necessárias, de acordo com cada realidade.

Sugerimos que o professor utilize esta sequência como uma forma de motivar os estudantes, descobrir suas dificuldades, levando o aluno a conhecer mais sobre o assunto investigado, contribuindo desse modo com a ação pedagógica do professor.

Este trabalho sugere a ideia de desenvolver novas sequências didáticas a partir de experimentos em outras áreas, como a Termodinâmica e Eletromagnetismo. Sugerimos, também, que o professor busque outros métodos de utilização do Arduino como ferramenta de ensino. A variedade de recursos que o Arduino oferece traz ao professor as alternativas de desenvolver inúmeras estratégias e habilidades para o ensino de Física.

\section{Referências}

Arce, A., Silva, D. A. S. M., \& Varotto, M. (2011). Ensinando ciências na educação infantil (2a ed.). Campinas: Alínea, 133.

Ausubel, D. P. (2003). Aquisição e retenção de conhecimentos: uma perspectiva cognitiva. Lisboa: Plátano, 1.

Bemfeito, A. P., \& Vianna, D. M. (2009). Investigações sobre ondas de rádio no ensino médio. XVIII Simpósio Nacional de Ensino de Física, Vitória.

Brasil/MEC. (2002). PCN+ Ensino Médio: orientações educacionais complementares aos Parâmetros Curriculares Nacionais. Ciências da Natureza, Matemática e suas Tecnologias. Brasília: MEC/SEMTEC. 
Research, Society and Development, v. 9, n. 9, e26996542, 2020

(CC BY 4.0) | ISSN 2525-3409 | DOI: http://dx.doi.org/10.33448/rsd-v9i9.6542

Bruno, I. F. (2009). Ensinar ciência no pré-escolar. Contributos para aprendizagens de outras áreas/domínios curriculares. Relato de experiências realizadas em jardins de infância. Enseñanza de las ciencias: revista de investigación y experiencias didácticas, (Extra), $5-8$.

Bzuneck, J. A., \& Boruchovitch, E. (2009). A motivação do aluno: contribuições da psicologia contemporânea. Petrópolis: Editora Vozes, 9-36.

Crestani, R. L. (2015). Motivação, inteligência e inteligência emocional e suas relações com o desempenho acadêmico (Dissertação de Mestrado, Universidade do Vale do Sapucaí). Pouso Alegre.

Etkina, E. (2015). Millikan award lecture: Students of physics-Listeners, observers, or collaborative participants in physics scientific practices? American Journal of Physics, 83, 669.

Ferreira, R. B. (2004). Galileu e a sua importância epistemológica. Millenium, 162-167.

Kaulfuss, M. A., \& Boruchovitch, E. (2016). Atribuições causais de professores para o sucesso e o fracasso em ensinar. Psicologia Escolar e Educacional, 20(2), 321-328.

Laburú, C. E. (2016). Seleção de experimentos de física no ensino médio: uma investigação a partir da fala de professores. Investigações em Ensino de ciências, 10(2), 161-178.

Lijnse, P. (2004). Didactical structures as an outcome of research on teaching-learning sequences?. International Journal of Science Education, 26(5), 537-554.

McRoberts, M. (2018). Arduino básico. São Paulo: Novatec Editora.

Moreira, M. A. (1999). Teorias de aprendizagem. V. 2. São Paulo: Editora pedagógica e universitária.

Moreira, M. A. (2017). Grandes desafios para o ensino da física na educação contemporânea. Revista do professor de Física, 1(1), 1-1 
Research, Society and Development, v. 9, n. 9, e26996542, 2020

(CC BY 4.0) | ISSN 2525-3409 | DOI: http://dx.doi.org/10.33448/rsd-v9i9.6542

Mourão, O. S. (2018). Uso da Plataforma Arduino como uma Ferramenta Motivacional para a Aprendizagem de Física. (Dissertação de Mestrado, Universidade Estadual Vale do Acaraú).

Nunes, H. M. (2018). Desenvolvimento e aplicação de um kit experimental com arduino para o ensino do eletromagnetismo, (Dissertação de Mestrado, Universidade Federal do Maranhão).

Paiva, F. F., Lemos Barbato, D. M., Fernandes Paiva, M. L. M., João, H. A., \& Muniz, S. R. (2018). Orientações motivacionais de alunos do ensino médio para física: considerações psicométricas. Revista Brasileira de Ensino de Física, 40(3).

Parisoto, M. F., \& Hilger, T. R. (2016). Investigação da aprendizagem de conceitos de óptica utilizando ilusões para turmas de pré-vestibular. Revista Brasileira de Ensino de Ciência e Tecnologia, 9(1).

Peduzzi, L. O. (1996). Física aristotélica: por que não considerá-la no ensino da mecânica. Caderno Catarinense de Ensino de Física, 13(1), 48-63.

Perassinoto, M. G. M., Boruchovitch, E., \& Bzuneck, J. A. (2013). Estratégias de aprendizagem e motivação para aprender de alunos do Ensino Fundamental. Avaliação psicológica, 12(3), 351-359.

Pereira, A. S., et al. (2018). Metodologia da pesquisa científica. [e-book]. Santa Maria. Ed. UAB/NTE/UFSM. Recuperado de https://repositorio.ufsm.br/bitstream /handle/1/15824/Lic_Computacao_Metodologia-Pesquisa-Cientifica.pdf?sequence=1.

Perez, A. L. F., Darós, R. R., Puntel, F. E., \& Vargas, S. R. (2013). Uso da Plataforma Arduino para o Ensino e o Aprendizado de Robótica. In International Conference on Interactive Computer aided Blended Learning.

Piaget, J., \& Fiúza, R. (2005). A representação do mundo na criança. Rio de Janeiro: Ideias e Letras.

Pinheiro Quibao, M., Carrillo Silva, A., de Almeida, N. S., Andrade Silva, R. M. A., Ricardo Muniz, S., \& Fernandes Paiva, F. (2019). Investigando a compreensão conceitual em física de 
Research, Society and Development, v. 9, n. 9, e26996542, 2020

(CC BY 4.0) | ISSN 2525-3409 | DOI: http://dx.doi.org/10.33448/rsd-v9i9.6542

alunos de graduação em cursos de ciências, engenharias e matemática. Caderno Brasileiro de Ensino de Física, 41(2).

Reis, F.(2015). Arduíno-Pinagem e anatomia de um Sketch(Projeto). Recuperado de http://www.bosontreinamentos.com.br/eletronica/arduino/arduino-pinagem-e-anatomia-deum-sketch-projeto/

Ricardo, E. C., \& Freire, J. C. (2007). The students' conceptions about high school's physics subject: an exploratory study. Revista Brasileira de Ensino de Física, 29(2), 251-266.

Rosito, B.A. (2003). O Ensino de Ciêncis a Experimentação. In Construtivismo e ensino de ciências: reflexões epistemológicas e metodológicas, 195-208. Porto Alegre: Edipucrs.

Rubim Junior, J. R. (2014). Microcontrolador Arduino no ensino de física: proposta e aplicação de uma situação de aprendizagem sobre o tema luz e cor. (Dissertação de Mestrado, Universidade Federal de São Carlos).

Santana, R. S., \& Franzolin, F. (2018). O ensino de ciências por investigação e os desafios da implementação na práxis dos professores. Revista de Ensino de Ciências e Matemática, 9(3), 218-237.

Schroeder, C. (2007). A importância da física nas quatro primeiras séries do ensino fundamental. Revista Brasileira de Ensino de Física, 29(1), 89-94.

Segatto, B. R., Buffon, L. O., Pereira, M. R., \& Gomes, T. D. S. (2016). Proposta de uma sequência didática sobre tópicos de física quântica através do uso de simulações computacionais e da determinação da constante de Plank com leds aplicado ao ensino médio (Dissertação de Mestrado, Universidade Federal do Espírito Santo).

Tavares, R. (2004). Aprendizagem significativa. Revista conceitos, 10(55).

Vidal, R. S. M. F. (2018). Ensino de termodinâmica através da construção de instrumentos de medição de variáveis meteorológicas e da confecção de mini estação meteorológica portátil com Arduino (Dissertação de Mestrado, Universidade Federal do Rio Grande do Norte). 
Von Korff, J., Archibeque, B., Gomez, K. A., Heckendorf, T., McKagan, S. B., Sayre, E.

C., Schenk, E.W., Shepherd, C., \& Sorell, L. (2016). Secondary analysis of teaching methods in introductory physics: A 50 k-student study. American Journal of physics, 84(12), 969-974.

\section{Porcentagem de contribuição de cada autor no manuscrito}

João Cláudio Nunes Carvalho - 50\%

Nickyson Brandão Everton - 50 \% 